\title{
Perfil industrial das exportações do Estado do Rio Grande do Sul e a hipótese de desindustrialização
}

\author{
Industrial profile of exports from the State of Rio Grande do Sul and the deindustrialization \\ hypothesis \\ Perfil industrial de las exportaciones en el Estado de Rio Grande do Sul y la hipótesis de la \\ desindustrialización
}

Recebido: 09/02/2021 | Revisado: 12/02/2021 | Aceito: 15/02/2021 | Publicado: 22/02/2021

\author{
Daniel Arruda Coronel \\ ORCID: https://orcid.org/0000-0003-0264-6502 \\ Universidade Federal de Santa Maria, Brasil \\ E-mail: daniel.coronel@uol.com.br \\ Leonardo Sangoi Copetti \\ ORCID: https://orcid.org/0000-0002-4801-4714 \\ Universidade Federal de Santa Maria, Brasil \\ E-mail: leonardocopetti@ hotmail.com
}

\begin{abstract}
Resumo
Este trabalho tem como objetivo analisar o perfil industrial do Estado do Rio Grande do Sul, visando responder à seguinte questão: está ocorrendo um processo de desindustrialização no Estado do Rio Grande do Sul? Nesse sentido, foram ajustados dois modelos Vetorial de Correção de Erro (VEC), com as seguintes variáveis dependentes: exportações da indústria de transformação (alta intensidade, média-alta, média-baixa e baixa intensidade) do Rio Grande do Sul e exportações de produtos não industriais desse estado. As variáveis independentes foram taxa de câmbio real efetiva; índice de preços das commodities não energéticas; e coeficiente do grau de abertura comercial. Os resultados indicaram que a desvalorização cambial estimula as exportações, que a abertura comercial foi extremamente prejudicial às exportações e que a variável índice de preço das commodities não energéticas apresentou sinal contrário ao esperado.
\end{abstract}

Palavras-chave: Indústria de transformação; Taxa de câmbio; Vetor de correção de erros.

\begin{abstract}
This paper aims to analyze the industrial profile of The State of Rio Grande do Sul, seeking to answer the following question: Is it occurring a process of deindustrialization in The State of Rio Grande do Sul? In this sense, were adjusted two Vector Error Correction Models (VEC), with the following dependent variables: exports of manufacturing industry (high intensity, mediumhigh, medium-low and low intensity) of The State of Rio Grande do Sul and exports of non-industrial products. The independent variables were real effective exchange rate; price index of non-energy commodities; and coefficient of the commercial openness degree. The results indicated that the exports of non-industrial products presented a greater increase than the products by technological intensity. In relation to the estimation of VEC, the results indicated that the exchange devaluation stimulates the exports; the commercial openness was extremely damaging to the exports and the price index of non-energy commodities variable presented opposite sign to the expected. Finally, we concluded that there are strong evidences of the deindustrialization process in The State of Rio Grande do Sul.
\end{abstract}

Keywords: Manufacturing industry; Exchange rate; Vector error correction.

\section{Resumen}

Este trabajo tiene como objetivo analizar el perfil industrial del estado de Rio Grande do Sul, con el objetivo de responder a la siguiente pregunta: ¿se está produciendo un proceso de desindustrialización en el estado de Rio Grande do Sul? En este sentido, se ajustaron dos modelos de Corrección de Error Vectorial (VEC), con las siguientes variables dependientes: exportaciones de la industria manufacturera (alta intensidad, media-alta, media-baja y baja intensidad) de Rio Grande do Sul y exportaciones de -productos industriales de ese estado. Las variables independientes fueron el tipo de cambio real efectivo; índice de precios de las materias primas no energéticas; y coeficiente del grado de apertura comercial. Los resultados indicaron que la devaluación del tipo de cambio estimula las exportaciones, que la apertura comercial fue sumamente perjudicial para las exportaciones y que el índice de precios variables de los productos básicos no energéticos mostró un signo contrario a las expectativas.

Palabras clave: Industria de la transformación; Tasa de cambio; Vector de corrección de errores. 


\section{Introdução}

O setor industrial é o motor do crescimento econômico, conforme Kaldor (1966); contudo, a indústria de transformação brasileira vem perdendo participação no Produto Interno Bruto (PIB) conforme dados do Instituto Brasileiro de Geografia e Estatística (IBGE, 2019), visto que sua participação, que chegou a perfazer 30\% do PIB na década de 1980, passou para 13,3\% em 2012 e, caso continue nesse ritmo, a projeção para 2029 é de menos de $10 \%$.

Essa forte queda acendeu o debate de que a economia brasileira está passando por um processo de desindustrialização. Entre os que defendem a tese da desindustrialização, estão economistas como Cano (2012), Marconi (2015), Pochmann (2016), Bresser-Pereira (2009a; 2011; 2019) e Coronel (2019, 2020).

Contudo, existem vários economistas como Barros e Pereira (2008), Jank et al. (2008) e Bonelli e Pessoa (2010) que não compactuam com esta visão, mas acreditam que o setor industrial brasileiro tem que superar desafios relacionados aos altos custos de transação, infraestrutura inadequada, problemas de logística, baixas taxas de investimento, elevada carga tributária, bem como instabilidade macroeconômica, o que tem feito com que a indústria venha perdendo competitividade.

Dada a importância do tema, vários trabalhos vêm sendo feitos visando analisar questões relacionadas à competitividade e à existência de um processo de desindustrialização na economia brasileira. Sonaglio et al. (2010) analisaram as evidências de um processo de desindustrialização na economia, por meio de dados em painel, e os resultados indicaram um possível processo de reprimarização da pauta de exportações brasileiras, o qual pode ser evidenciado pela redução das exportações dos bens de alta intensidade tecnológica e aumento de bens não industriais.

Cano (2012) analisou a relação entre o processo de desindustrialização e a política macroeconômica mediante uma ampla revisão de literatura, e os resultados indicaram que esse processo tem se acentuado devido à ausência de políticas industriais, bem como de políticas macroeconômicas de cunho desenvolvimentista.

Pereira e Cario (2017) sistematizaram o tratamento analítico sobre os estudos e pesquisas de desindustrialização através de uma revisão de literatura, e os resultados indicaram a existência de quatro escolas de pensamento: UNICAMP, FGV-SP, PUC-RJ e UFRGS.

Não obstante a isso, a maior parte dos estudos tem como foco o país, não abordando os impactos nas macrorregiões ou nos estados brasileiros, os quais têm peculiaridades que podem influenciar na dinâmica desse processo.

Nesse sentido, seguindo esta temática, mas com foco regional, este trabalho tem como problema de pesquisa responder à seguinte questão: está ocorrendo um processo de desindustrialização no Estado do Rio Grande do Sul? Objetivamente visa-se verificar os prenúncios de desindustrialização na economia brasileira, enfatizando o Estado do Rio Grande do Sul.

De acordo com o Ministério do Desenvolvimento, Indústria e Comércio (MDIC, 2021), o Estado do Rio Grande do Sul foi responsável em média, de 2007 a 2018, por aproximadamente 2,76\% das exportações dos produtos de alta intensidade tecnológica, por 11,09\% dos de média-alta intensidade tecnológica, por 6,06\% dos de média baixa, por 11,47\% dos de baixa intensidade tecnológica e por 7,46\% dos produtos não industriais em relação à média brasileira.

Apesar da importante participação, ainda há uma lacuna a ser preenchida visando analisar com maior acuidade o perfil exportador do Estado, bem como para quais mercados estão direcionados os produtos da pauta exportadora e quais os produtos que mais se destacam.

A partir das respostas a essas questões, será possível formular estratégias e ações visando aumentar a competitividade do setor, bem como políticas industriais que efetivamente sejam eficazes para uma reconfiguração industrial, não apenas meras reduções e isenções tarifarias. 
Nesse sentido, o presente trabalho se propõe a mostrar empiricamente se este Estado passa por um processo de desindustrialização e quais variáveis econômicas podem auxiliar a reversão ou o aprofundamento desse processo, visando a uma reestruturação produtiva no setor industrial.

O presente trabalho está dividido em quatro seções, além desta introdução. A seção dois apresenta a revisão de literatura, em que se explicita o conceito, as causas e as soluções para o processo de desindustrialização. Posteriormente, faz-se análise do perfil das exportações do Rio Grande do Sul. Na seção seguinte, apresentam-se os procedimentos metodológicos utilizados na pesquisa. Na seção quatro, analisam-se os resultados da estimação dos modelos e, por fim, são apresentadas as conclusões do trabalho, destacando-se as limitações da pesquisa e as perspectivas para trabalhos futuros.

\section{Revisão de Literatura}

\subsection{Desindustrialização: causas e consequências}

O crescimento econômico pode ser mais bem esboçado e analisado através das seguintes relações: a) existência de uma relação positiva entre o crescimento da indústria e o crescimento do produto agregado, ou seja, quanto maior for a taxa de crescimento do setor industrial, maior será a do produto nacional; b) uma correlação positiva entre o crescimento do produto industrial e da produtividade industrial; nesse sentido, constata-se uma relação de causalidade, pois, quanto maior for a taxa de crescimento da indústria, maior será a taxa de crescimento da produtividade; c) a longo prazo, o crescimento da economia não seria restrito pela oferta, mas pela sua demanda; nesse contexto, a restrição de demanda ao crescimento do produto em uma economia aberta seria o balanço de pagamentos (Kaldor, 1957; 1978).

Ainda nessa perspectiva, o setor industrial seria como um indutor do crescimento econômico, visto que este gera encadeamentos produtivos, economias de escala e externalidades para outros setores. Esse transbordamento das atividades industriais para os demais setores está relacionado à absorção de produtos e commodities produzidos no setor agrícola e de mineração, além da contratação de diversos tipos de serviços (Kaldor, 1966).

Para autores como Szirmai (2012), Acemoglu e Robinson (2012), Bresser-Pereira, Oreiro e Marconi (2016) e Reinert (2016), todos os países que se desenvolveram tiveram seu modelo de crescimento puxado pelo setor industrial, visto que a produtividade nesse setor é maior do que na agricultura; o setor industrial oferece mais oportunidades de economias de escala que o setor agrícola, e os efeitos de encadeamento e transbordamento são maiores do que na agricultura.

A economia brasileira iniciou tardiamente o seu processo de industrialização, o qual teve um novo impulso a partir do Governo Vargas, na década de 1930, quando tem início o Processo de Substituição de Importações (PSI), que vai até o final da década de 1980 e que adotou as seguintes medidas: desvalorização cambial; taxas múltiplas de câmbio; crédito e subsídios; elevadas tarifas de importação e forte participação do Estado, através de infraestrutura, logística e do arcabouço legal e institucional (Coronel, Azevedo \& Campos, 2014).

Da década de 1990 até meados de 2000, foram poucas as ações para fomentar a competitividade do setor industrial, visto que o foco, no Brasil e demais países latino-americanos, era o controle das taxas de inflação e a busca pela estabilidade macroeconômica (Peres, 2006).

Ainda nessa perspectiva, a perda de competitividade do setor industrial brasileiro, ao longo dos anos 2000, começou a levantar debates e discussões sobre se a economia brasileira estava passando por um processo de desindustrialização, o qual pode ser entendido como a redução persistente da participação do emprego industrial relativamente ao emprego total, bem como queda da participação do setor industrial no PIB (Rowthorm \& Ramaswamy, 1999; Oreiro \& Feijo, 2010; BresserPereira, 2011, 2019).

De acordo com Bresser-Pereira (2011), os países desenvolvidos, a partir de certo nível de renda per capita, começam a se desindustrializar devido à concorrência de países em que a mão de obra é mais barata. Como consequência, esses países 
deixam de produzir bens industriais, especialmente de baixa tecnologia, transferindo sua mão de obra para setores de serviços com maior intensidade tecnológica e níveis de renda e de valor adicionado per capita mais alto, portanto, com salários médios mais altos. Quando esse processo ocorre desta forma, a desindustrialização não é prejudicial. No entanto, em países como o Brasil, que têm uma renda per capita baixa, esse processo de transformação estrutural é prematuro.

Para Bresser-Pereira, Oreiro e Marconi (2016), quando um país passa por um processo de desindustrialização, algumas medidas devem ser adotadas, tais como desvalorização cambial, política industrial ativa, maiores investimentos em infraestrutura e sofisticação produtiva, ou seja, uma maior diversificação da produção com ênfase em setores de média e alta intensidade tecnológica.

Os principais efeitos do processo de desindustrialização em países em desenvolvimento como o Brasil são a) queda na renda dos trabalhadores; b) especialização regressiva, com retorno às vantagens comparativas baseadas em recursos naturais (Teoria das Vantagens Comparativas); c) tendência a desequilíbrios externos; d) quedas nas taxas de investimento; e) queda no Produto Interno Bruto (PIB); f) aumento da importação de produtos industriais, sendo que as causas para tal processo estão relacionadas sobrevalorização cambial, abertura econômica, altas taxas de juros, infraestrutura inadequada e alto custo Brasil (Cano; 2012, 2014; Benjamim, 2015).

Uma das formas de combater o processo de desindustrialização é por meio de políticas industriais, cujos principais instrumentos são a isenção tributária, a oferta de juros subsidiados, a discricionariedade da estrutura de tarifas de importação, a redução do Imposto sobre Produtos Industrializados (IPI) e do Imposto sobre Circulação de Mercadorias (ICMS) e medidas visando melhorar a infraestrutura e a redução de custos sistêmicos ou custos de transação (Kupfer, 2003; Pack; Saggi, 2006; Coronel, Azevedo \& Campos, 2014).

Desde 2000, três políticas industriais foram utilizadas para fomentar a competitividade do setor industrial brasileiro: a Política Industrial, Tecnológica e de Comércio Exterior (PITCE), que deixou como legado apenas a criação de marcos regulatórios, como a Lei da Inovação e da Biossegurança; a Política de Desenvolvimento Produtivo (PDP), que tinha como foco os setores de média-alta e alta intensidade tecnológica e se mostrou totalmente ineficiente para esses setores; por fim, a Política Brasil Maior, também com foco nos setores de alta intensidade tecnológica, mas que não atingiu boa parte de suas metas e ainda teve forte relação com a crise macroeconômica iniciada em 2014 (Soares, Coronel, Marion Filho, 2013; Coronel, Azevedo \&Campos, 2014; Nassif, 2019; Stumm, Nunes \& Perissinotto; 2019).

\subsection{Padrão de especialização das exportações do Estado do Rio Grande do Sul}

Segundo o Instituto Brasileiro de Geografia e Estatísticas (IBGE, 2021), o Rio Grande do Sul é o quarto estado com maior participação no PIB nacional, visto que, de 2007 a 2018, apresentou uma média de 6,20\% do PIB do país.

Em relação às exportações do Estado do Rio Grande do Sul, de acordo com o Ministério do Desenvolvimento, Indústria e Comércio Exterior (MDIC, 2021), em 2018, elas totalizaram US\$ 21,01 bilhões (4a posição no ranking de exportação dos estados brasileiros, com uma participação de 8,76\% nas exportações do país). Em relação às importações do estado do RS, o valor total foi de US $\$ 11,28$ bilhões ( $5^{\text {a }}$ posição dos estados brasileiros, com uma participação de 6,22\%).

Segundo o MDIC (2021), a China foi o principal destino das exportações do estado em 2018, com um total de US\$ 5,69 bilhões, representando 27,08\% das exportações totais do RS seguida pela Holanda com US\$ 1,76 bilhões (8,38\%) e a Argentina com US\$1,46 bilhões (6,95\%). Além disso, os principais produtos exportados pelo Rio Grande do Sul foram: soja, mesmo triturada com US \$ 4,53 bilhões (21,56\%); barcos e estruturas flutuantes com US\$2,83 bilhões (13,47\%) e tabaco não manufaturado com US\$ 1,47 bilhões $(7,00 \%)$. 
Na Tabela $1^{1}$, encontra-se a composição das exportações do estado do Rio Grande do Sul por setor de atividade econômica, de 2007 a 2018.

Tabela 1 - Composição das exportações do Estado do Rio Grande do Sul por setor da atividade econômica - 2007-2018.

\begin{tabular}{ccccccccc}
\hline \multirow{2}{*}{ Ano } & \multicolumn{2}{c}{ Produtos não industriais } & \multicolumn{2}{c}{$\begin{array}{c}\text { Indústria da } \\
\text { transformação }\end{array}$} & \multicolumn{2}{c}{ Demais produtos } & \multicolumn{2}{c}{ Total } \\
\cline { 2 - 9 } & $\begin{array}{c}\text { Em bilhões } \\
\text { de US\$ }\end{array}$ & $\%$ & $\begin{array}{c}\text { Em bilhões de } \\
\text { US\$ }\end{array}$ & $\%$ & $\begin{array}{c}\text { Em bilhões } \\
\text { de US\$ }\end{array}$ & $\%$ & $\begin{array}{c}\text { Em bilhões } \\
\text { de US\$ }\end{array}$ & $\%$ \\
\hline 2007 & 3,38 & 22,67 & 11,36 & 76,24 & 0,16 & 1,09 & 14,90 & 100 \\
2008 & 4,03 & 22,00 & 14,09 & 76,86 & 0,21 & 1,14 & 18,33 & 100 \\
2009 & 5,34 & 35,15 & 9,76 & 64,20 & 0,10 & 0,65 & 15,20 & 100 \\
2010 & 3,96 & 25,85 & 11,25 & 73,36 & 0,12 & 0,79 & 15,33 & 100 \\
2011 & 5,42 & 28,43 & 13,48 & 70,66 & 0,17 & 0,91 & 19,08 & 100 \\
2012 & 5,03 & 29,01 & 12,08 & 69,73 & 0,22 & 1,26 & 17,33 & 100 \\
2013 & 7,46 & 29,79 & 17,36 & 69,27 & 0,23 & 0,94 & 25,05 & 100 \\
2014 & 6,49 & 34,80 & 11,93 & 63,96 & 0,23 & 1,24 & 18,66 & 100 \\
2015 & 6,32 & 36,11 & 10,99 & 62,75 & 0,20 & 1,14 & 17,51 & 100 \\
2016 & 5,80 & 34,95 & 10,67 & 64,38 & 0,11 & 0,67 & 16,58 & 100 \\
2017 & 6,66 & 37,48 & 10,99 & 61,83 & 0,12 & 0,70 & 17,78 & 100 \\
2018 & 7,13 & 33,93 & 13,79 & 65,63 & 0,09 & 0,44 & 21,01 & 100 \\
\hline
\end{tabular}

Fonte: Autores a partir de dados da FUNCEX (2021)

Pela análise da Tabela 1, observa-se uma redução de 10,61\% na participação das exportações da indústria da transformação, passando de 76,24\%, em 2007, para 65,63\%, em 2018.

O setor não industrial apresentou um aumento de 11,26\%, passando de 22,67\%, em 2007, para 33,93\%, em 2018, já os demais produtos apresentaram um declínio de $0,65 \%$.

A Tabela 2 ilustra as taxas geométricas de crescimento ${ }^{2}$ das exportações da indústria de transformação e dos produtos não industriais para o Rio Grande do Sul e para a economia brasileira, no período de 2007 a 2018.

Tabela 2 - Taxas geométricas de crescimento das importações e exportações do Estado do Rio Grande do Sul e do Brasil por setor da atividade econômica - 2007-2018.

\begin{tabular}{ccccc}
\hline \multirow{2}{*}{ Taxa de crescimento (\%) } & \multicolumn{2}{c}{ Rio Grande do Sul } & \multicolumn{2}{c}{ Brasil } \\
\cline { 2 - 5 } & Exportações & Importações & Exportações & Importações \\
\hline Produtos não industriais & $5,97 \%$ & $5,67 \%$ & $5,23 \%$ & $-3,36 \%$ \\
Indústria de transformação & $0,14 \%$ & $0,96 \%$ & $0,80 \%$ & $2,00 \%$ \\
Total & $1,79 \%$ & $1,63 \%$ & $2,13 \%$ & $1,29 \%$ \\
\hline
\end{tabular}

Fonte: Autores a partir de dados da FUNCEX (2021)

Com base nos dados da Tabela 2, é possível verificar que o crescimento das exportações dos produtos não industriais, do Estado do Rio Grande do Sul e do Brasil foram cinco vezes maior do que a indústria de transformação. Já as importações da

\footnotetext{
${ }^{1}$ De acordo com a classificação da Organização para a Cooperação e Desenvolvimento Econômico (OCDE, 2019), a indústria de transformação compreende os segmentos de alta intensidade, média-alta, média-baixa e baixa intensidade.

${ }^{2}$ Segundo Greene (2008), a taxa geométrica de crescimento da variável Y pode ser descrita por: $\ln Y_{1}=\beta_{1}+\beta, 1+u$, representando a função log-linear teórica para a taxa de crescimento “t”, onde $u_{*}$ é um termo de erro aleatório, $\beta_{2}$ é a taxa de crescimento instantânea (em um ponto do tempo), e a taxa de

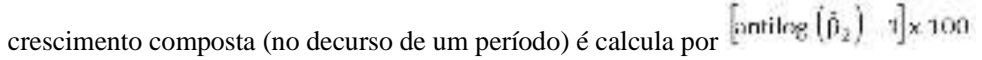


indústria de transformação cresceram a taxas moderadas, no Rio Grande do Sul e no Brasil, de, respectivamente, 0,96\% e $2,00 \%$.

Na Tabela 3, encontram-se as exportações do Estado do Rio Grande do Sul e do Brasil segundo o grau de intensidade tecnológica, em 2007 e 2018.

Tabela 3 - Exportações e importações, segundo o grau de intensidade tecnológica do Estado do Rio Grande do Sul e do Brasil $-2007 / 2018$.

\begin{tabular}{|c|c|c|c|c|c|c|c|c|}
\hline \multicolumn{9}{|c|}{ Exportação } \\
\hline País/ região & \multicolumn{4}{|c|}{ Rio Grande do Sul } & \multicolumn{4}{|c|}{ Brasil } \\
\hline \multirow[b]{2}{*}{ Ano } & \multicolumn{2}{|c|}{2007} & \multicolumn{2}{|c|}{2018} & \multicolumn{2}{|c|}{2007} & \multicolumn{2}{|c|}{2018} \\
\hline & $\begin{array}{c}\text { Em } \\
\text { bilhões } \\
\text { de US\$ }\end{array}$ & $\%$ & $\begin{array}{c}\text { Em } \\
\text { bilhões } \\
\text { de US\$ }\end{array}$ & $\%$ & $\begin{array}{c}\text { Em } \\
\text { bilhões } \\
\text { de US\$ }\end{array}$ & $\%$ & $\begin{array}{c}\text { Em } \\
\text { bilhões } \\
\text { de US\$ }\end{array}$ & $\%$ \\
\hline Produtos não industriais & 3,38 & 22,67 & 7,13 & 33,93 & 38,70 & 24,11 & 99,14 & 41,33 \\
\hline Baixa & 5,94 & 39,89 & 5,53 & 26,32 & 41,88 & 26,09 & 52,74 & 21,99 \\
\hline Média-baixa & 1,20 & 8,07 & 3,86 & 18,35 & 28,80 & 17,94 & 37,65 & 15,70 \\
\hline Média-alta & 3,97 & 26,64 & 4,12 & 19,60 & 38,50 & 23,98 & 37,17 & 15,50 \\
\hline Alta & 0,24 & 1,64 & 0,29 & 1,36 & 9,65 & 6,01 & 10,96 & 4,57 \\
\hline Demais produtos & 0,16 & 1,09 & 0,09 & 0,44 & 2,99 & 1,87 & 2,22 & 0,93 \\
\hline Total & 14,90 & 100,00 & 21,01 & 100,00 & 160,52 & 100,00 & 239,89 & 100,00 \\
\hline \multicolumn{9}{|c|}{ Importação } \\
\hline País/região & \multicolumn{4}{|c|}{ Rio Grande do Sul } & \multicolumn{4}{|c|}{ Brasil } \\
\hline & \multicolumn{2}{|c|}{2007} & \multicolumn{2}{|c|}{2018} & \multicolumn{2}{|c|}{2007} & \multicolumn{2}{|c|}{2018} \\
\hline Ano & $\begin{array}{c}\text { Em } \\
\text { bilhões } \\
\text { de US\$ }\end{array}$ & $\%$ & $\begin{array}{c}\text { Em } \\
\text { bilhões } \\
\text { de US\$ }\end{array}$ & $\%$ & $\begin{array}{c}\text { Em } \\
\text { bilhões } \\
\text { de US\$ }\end{array}$ & $\%$ & $\begin{array}{c}\text { Em } \\
\text { bilhões } \\
\text { de US\$ }\end{array}$ & $\%$ \\
\hline Produtos não industriais & 1,36 & 17,58 & 1,82 & 16,15 & 20,80 & 17,26 & 18,01 & 9,94 \\
\hline Baixa & 0,52 & 6,69 & 0,59 & 5,19 & 8,02 & 6,66 & 14,31 & 7,89 \\
\hline Média-baixa & 1,67 & 21,63 & 2,38 & 21,14 & 19,81 & 16,44 & 43,22 & 23,85 \\
\hline Média-alta & 3,81 & 49,33 & 5,90 & 52,31 & 51,42 & 42,68 & 77,37 & 42,69 \\
\hline Alta & 0,37 & 4,78 & 0,59 & 5,21 & 20,43 & 16,96 & 28,32 & 15,63 \\
\hline Total & 7,72 & 100,00 & 11,28 & 100,00 & 120,48 & 100,00 & 181,23 & 100,00 \\
\hline
\end{tabular}

Fonte: Autores a partir de dados da FUNCEX (2021)

Conforme dados da Tabela 3, os produtos não industriais foram os que apresentaram maior aumento na participação das exportações, tanto do Rio Grande do Sul como nos do país. Além disso, apresentaram decréscimo em suas importações.

Em relação à análise por intensidade tecnológica, os dados mostram que todos os setores classificados por esse tipo de intensidade apresentaram um crescimento menor em suas exportações, se comparados aos produtos não industriais, tanto para a Região Sul como para o Brasil, o que corrobora fortemente com as pesquisas dos economistas do Novo-Desenvolvimentismo que apregoam que os preços das commodities levam à apreciação da taxa de câmbio, que, por sua vez, leva à perda de competitividade nas exportações de manufaturados, ou seja, dos produtos com maior intensidade tecnológica (Teixeira; Coronel; Oreiro, 2019).

Nesse sentido, essa vertente preconiza uma taxa de equilíbrio industrial visando fomentar a competitividade do setor industrial e estancar o processo de desindustrialização, conforme Marconi e Rocha (2011), Benjamin (2015), Mattei e Scaramuzzi (2016), Bresser-Pereira (2019) e Teixeira, Coronel e Oreiro (2019). 
Por fim, a análise das importações por intensidade tecnológica indicou aumento para boa parte dos setores tanto para o Rio Grande do Sul como para o Brasil, o que tem forte relação com o câmbio apreciado e com a abertura econômica desordenada.

\section{Metodologia}

A presente pesquisa é caracterizada como quantitativa e explicativa (Pereira et al., 2018). Como fontes de dados secundários foram utilizados os dados coletados nos seguintes sites: Fundação do Centro de Estudos do Comércio Exterior FUNCEX (2021), no Instituto de Economia Aplicada - IPEA (2021), no World Bank (2021) e no Instituto Brasileiro de Geografia e Estatística - IBGE (2021).

\subsection{Modelo Analítico}

Para determinar a ordem de integração das séries de interesse, este trabalho utilizou os testes de raiz unitária DickeyFuller Aumentado (Dickey; Fuller, 1979, 1981) e Kwiatkowski, Phillips, Schmidt e Shin (KPSS, 1992). Esses testes permitem verificar a existência ou não de raízes unitárias nas séries temporais, ou seja, se as variáveis são ou não estacionárias ${ }^{3}$. A utilização dos dois testes em conjunto para o diagnóstico de estacionariedade das séries temporais relaciona-se a uma maior confiabilidade e robustez dos resultados. O teste ADF consiste na estimação da seguinte equação por Mínimos Quadrados Ordinários e pode ser expresso, conforme Enders (1995), da seguinte forma:

$$
\Delta y_{t}=\alpha_{0}+\gamma y_{t-1}+\sum_{i=2}^{p} \beta_{i} \Delta y_{t-i+1}+\varepsilon_{t}
$$

com: $\gamma=-\left(1-\sum_{i=1}^{p} \alpha_{i}\right)$ e $\beta_{i}=\sum_{j=i}^{p} \alpha_{j}$,

em que: $\alpha_{0}$ é o intercepto; $\gamma$ descreve o comportamento da série temporal; $y$ representa a variável dependente; $\Delta$ é a representação do operador de diferença e $\varepsilon_{t}$ denota o erro que se assume ser idêntica e independentemente distribuída. A fim de determinar o número de defasagens utilizadas no teste para eliminar a autocorrelação residual, utilizou-se o menor valor do critério de Schwarz (SBC).

O parâmetro de interesse nas regressões (sem intercepto e sem tendência; com intercepto; com intercepto e tendência) é $\gamma$, sendo que, se $\gamma=\mathbf{O}$, a série contém uma raiz unitária. Nesse teste, compara-se o resultado da estatística $\tau$ com os valores apropriados reportados por Dickey-Fuller para determinar se aceita ou se rejeita a hipótese nula $\gamma=0$. A hipótese nula será rejeitada se o valor calculado da estatística $\tau$ for maior do que o valor crítico de Dickey-Fuller, indicando que a série é estacionária; caso contrário, a série é não estacionária.

O KPSS é um teste alternativo ao ADF, partindo da hipótese nula de estacionariedade, conforme Greene (2008). Formalmente é expresso pela seguinte expressão:

\footnotetext{
${ }^{3}$ Um processo estocástico é estacionário quando a sua média e a sua variância são constantes ao longo do tempo e quando o valor da covariância entre dois períodos de tempo depende apenas da distância, do intervalo ou da defasagem entre os períodos de tempo, e não do próprio tempo em que a covariância é calculada. Em notação matemática, as propriedades do processo estocástico estacionário podem ser representadas por: (Média) $E\left(Y_{t}\right)=\mu$, $($ ariância) $\operatorname{var}\left(Y_{t}\right)=E\left(Y_{t}-u\right)^{2}=\sigma^{2}$ e (Covariância) $\gamma_{k}=E\left[\left(Y_{t}-\mu\right)\left(T_{t+k}-\mu\right)\right]$. Um processo estocástico com as propriedades descritas anteriormente é conhecido, na literatura de séries temporais, como processo fracamente estacionário, ou estacionário em covariância, ou estacionário de segunda ordem, ou estacionário em sentido amplo. Um processo estocástico é fortemente estacionário quando todos os momentos de sua distribuição não variam ao longo do tempo (Bueno, 2008.)
} 


$$
\begin{aligned}
& y_{t}=\alpha+\beta t+\gamma \sum_{i=1}^{t} z_{i}+\varepsilon_{t} \\
& y_{t}=\alpha+\beta_{t}+\gamma Z_{t}+\varepsilon_{t}
\end{aligned}
$$

tendo as seguintes hipóteses:

$$
\begin{aligned}
& H_{0}: \gamma=0, \text { série é estacionária; } \\
& H_{a}: \gamma \neq 0, \text { série é não estacionária. }
\end{aligned}
$$

\subsection{Análise de cointegração}

Mesmo que variáveis individuais não sejam estacionárias, mas exista pelo menos uma combinação linear estacionária entre elas, então se pode afirmar que essas variáveis são cointegradas (Greene, 2008), ou seja, é possível verificar uma relação de equilíbrio de longo prazo entre elas, que pode ser estimada e analisada ${ }^{4}$. Dessa forma, para identificar o possível relacionamento de longo prazo entre as séries, utilizou-se o teste de cointegração elaborado por Johansen (1988).

O procedimento de Johansen (1988) considera que todas as variáveis são endógenas e sua utilização não é limitada pela existência de endogeneidade do regressor (relação causal no sentido da variável dependente para a variável explicativa). Esse procedimento utiliza Máxima Verossimilhança para estimar os vetores de cointegração e permite testar e estimar a presença de vários vetores e não só de um único vetor de cointegração.

De acordo com Harris (1995), definido um vetor $z_{t}$ de $n$ variáveis potencialmente endógenas, é possível especificar o seguinte processo gerador, e modelar $z_{t}$ como um Vetor Auto-regressivo (VAR) irrestrito com k defasagens de $z_{t}$ :

$$
z_{t}=A_{1} z_{t-1}+\ldots+A_{k} z_{t-k}+u_{t}
$$

em que: $z_{t}$ é um vetor $(n x l), A_{i}$ é uma matriz de parâmetros $(n x n)$ e $u_{t} \sim \boldsymbol{I I D}\left(\boldsymbol{\mu}, \boldsymbol{\sigma}^{2}\right)$.

Ainda conforme Harris (1995), a Equação (7) pode ser reparametrizada em termos de um modelo Vetorial de Correção de Erro (VEC) esboçado como:

$$
\Delta z_{t}=\Gamma_{1} \Delta z_{t-1}+\ldots+\Gamma_{k-1} \Delta z_{t-k+1}+\prod z_{t-k}+\varepsilon_{t}
$$

em que $: \boldsymbol{\Gamma}_{i}=-\left(\boldsymbol{I}-\boldsymbol{A}_{1}-\cdots-\boldsymbol{A}_{\boldsymbol{i}}\right),(\mathrm{i}=1, \ldots, \mathrm{k}-1)$ e $\boldsymbol{\Pi}=-\left(\boldsymbol{I}-\boldsymbol{A}_{1}-\cdots \boldsymbol{A}_{\boldsymbol{k}}\right)$. Da forma como especificado, o sistema contém informações de curto e longo prazo a mudanças de $z_{t}$, via estimativas de $\hat{\Gamma}_{i}$ e $\hat{\Pi}$, respectivamente, onde $\Pi=\alpha \beta^{\prime}$, com $\alpha$ representando a velocidade de ajustamento ao desequilíbrio e $\beta$ a matriz de coeficientes de longo prazo.

A importância do modelo de correção de erro reside no fato de permitir a ligação entre aspectos relacionados à dinâmica de curto prazo com os de longo prazo (HAMILTON, 1994). Dessa forma, os mecanismos de correção de erro pretendem fornecer um caminho para combinar as vantagens de se modelar tanto em nível quanto nas diferenças. Nesse

\footnotetext{
${ }^{4}$ Engle e Granger (1987) mostram que, se todas as séries de interesse possuem a mesma ordem de integração $I(d)$ e existir um vetor $\alpha$, com $\alpha \neq 0$, em que a combinação linear dessas variáveis seja de ordem $d-b, Z_{t}=\alpha^{\prime} X_{t} \sim I(d-b), b>0$, pode-se afirmar que $X_{t}$ é um vetor de variáveis cointegradas denotadas por $X_{t} \sim C I(d, b)$.
} 
modelo, não apenas a dinâmica do processo de ajustamento de curto prazo como também a do processo de longo prazo são modeladas simultaneamente.

O número de vetores de cointegração depende do posto ou rank $(r)$ da matriz $\Pi$ I. Em termos de vetores de cointegração, têm-se três possibilidades, conforme Enders (1995): se o posto de $\Pi$ é completo, então as variáveis $Y_{t}$ são $\mathrm{I}(0)$, ou seja, significa que qualquer combinação linear entre as variáveis é estacionária e o ajuste do modelo deve ser efetuado com as variáveis em nível; se o posto de $\Pi$ é zero, então não há relacionamento de cointegração e o modelo deve ser ajustado com as variáveis em diferença e, quando $\Pi$ tem posto reduzido, há $r$ vetores de cointegração.

Para Enders (1995), o rank de uma matriz é igual ao número de raízes características estritamente diferentes de zero, que pode ser identificado por meio de dois testes estatísticos. O primeiro deles é o teste do traço, que testa a hipótese nula de que o número de vetores de cointegração distintos é menor ou igual a $\mathrm{r}$ contra a hipótese alternativa de que o número desses vetores é maior do que $\mathrm{r}$, que pode ser definido por:

$$
\lambda_{\text {trace }}(r)=-T \sum_{i=r+1}^{n} \ln \left(1-\lambda_{i}^{\prime}\right)
$$

em que:

$\lambda_{i}^{\prime}=$ valores estimados das raízes características obtidos da matriz $\Pi ; T=$ número de observações.

O segundo teste é o do máximo autovalor, que testa a hipótese nula de que o número de vetores de cointegração é $r$ contra a hipótese alternativa de existência de $r+1$ vetores de cointegração, podendo ser expresso da seguinte forma:

$$
\lambda_{\max }(r, r+1)=-T \ln \left(1-\lambda_{r+1}^{\prime}\right)
$$

Verificada a cointegração entre as séries analisadas, estima-se o modelo VEC, conforme definido na Expressão (4).

Visando responder ao problema de pesquisa e atingir os objetivos do presente trabalho, estimaram-se dois modelos econométricos, um com a indústria de transformação (alta intensidade, média-alta, média-baixa e baixa intensidade) e outro com os produtos não industriais do Estado de Santa Catarina, como variáveis dependentes, baseados nos estudos de Veríssimo (2010), Veríssimo e Araújo (2016) e Souza e Veríssimo (2019).

As variáveis utilizadas para o ajuste do modelo foram:

INDTRANSF: exportações da indústria de transformação (alta intensidade, média-alta, média-baixa e baixa intensidade do Estado do Rio Grande do Sul;

PNI: exportações de produtos não industriais do Rio Grande do Sul;

TCREF: taxa de câmbio real efetiva - exportações - Índice Nacional de Preços ao Consumidor (INPC);

IPCOM: índice de preços das commodities não energéticas; e

ABERT: coeficiente do grau de abertura comercial - soma das exportações e importações totais em relação ao PIB do Estado do Rio Grande do Sul - proxy para avaliar se a abertura comercial favoreceu a substituição da produção industrial interna por importações.

Os dados para estimação dos parâmetros foram coletados nos seguintes sites: na Fundação do Centro de Estudos do Comércio Exterior - FUNCEX (2021), para as variáveis exportações do Estado do Rio Grande do Sul da indústria da transformação (em dólares - US\$), e exportações do Estado do Rio Grande do Sul dos produtos não industriais (em dólares US\$); no Instituto de Pesquisa Econômica Aplicada - IPEA (2021), para a variável taxa de câmbio - real efetiva - INPC exportações (em reais por dólares - R \$/ US\$); no World Bank (2021), para a variável índice de preços das commodities não energéticas; e na FUNCEX (2021) e no Instituto Brasileiro de Geografia e Estatística - IBGE (2021), para a variável 
coeficiente de abertura comercial do Rio Grande do Sul (somatório das importações e exportações totais do Rio Grande do Sul, dividido pelo PIB deste estado). O período analisado foi o de janeiro de 2007 a dezembro de 2018, com cotações mensais, totalizando 144 observações.

Convém destacar que esse período compreende o início do II Governo Lula, quando as comodities tiveram um aumento expressivo em suas exportações - a crise do subprime -, e os Governos Dilma I, Dilma II e Temer, sendo que os dois últimos enfrentaram uma forte restrição macroeconômica, a qual afetou as exportações brasileiras e contribuiu para um quadro de estagnação econômica.

Na Tabela 4, encontra-se um resumo das variáveis que foram utilizadas no modelo.

Tabela 4 - Variáveis utilizadas no modelo e as respectivas siglas.

\begin{tabular}{cc}
\hline Variável & Sigla \\
\hline Exportações da indústria de transformação do Rio Grande do Sul & INDTRANSF \\
Exportações dos produtos não industriais do Rio Grande do Sul & PNI \\
Taxa de câmbio real efetiva & CREF \\
Índice de preços das commodities não energéticas & LIPCOM \\
Coeficiente de abertura comercial & ABERT \\
\hline
\end{tabular}

Fonte: Autores.

A série exportações dos produtos não industriais do Estado do Rio Grande do Sul (PNI) foi dessazonalizada pelo método Seazonal-trend Decomposition - STL do software Eviews 11 e teve seu nome alterado para TNI_STL. A seguir, foi aplicado o logaritmo neperiano sobre todas as séries e seus nomes foram alterados acrescentando um ' $L$ ' no início.

A estimação dos parâmetros e a realização dos testes econométricos ocorreram por meio do software Eviews 11, sendo utilizado em todas as análises um nível de significância de 5\%.

\section{Resultados e Discussão}

\subsection{Testes de raiz unitária}

Para dar início à estimação dos parâmetros dos modelos econométricos, foram realizados os testes de estacionariedade: ADF - Dickey-Fuller Aumentado; e KPSS - Kwiatkoswski, Philips, Schmidt e Shin. Os resultados estão expostos nas Tabelas 5 e 6.

Tabela 5 - Testes de raiz unitária em nível aplicados nas séries mensais das exportações do Estado do Rio Grande do Sul da indústria da transformação e produtos não industriais (em US\$), taxa de câmbio real efetiva (R\$/ US\$), índice dos preços das commodities não energéticas e coeficiente de abertura comercial no período de janeiro de 2007 a dezembro de 2018

\begin{tabular}{ccccccc}
\hline & \multicolumn{3}{c}{ Teste ADF } & \multicolumn{3}{c}{ Teste KPSS } \\
\hline Séries & Modelo & \multicolumn{2}{c}{ Estatística de teste } & \multicolumn{2}{c}{ Modelo } & \multicolumn{2}{c}{ Estatística de teste } \\
\hline LINDTRANSF & constante & -5.632175 & $* * *$ & constante & 0.093720 & $\mathrm{~ns}$ \\
LPNI_STL & constante & -3.666201 & $* * *$ & constante & 1.173013 & $* * *$ \\
LTCREF & constante & -1.623778 & $\mathrm{~ns}$ & constante & 0.722589 & $* *$ \\
LIPCOM & constante & -2.339867 & $\mathrm{~ns}$ & constante & 0.485600 & $* *$ \\
LABERT & constante & -6.156364 & $* * *$ & constante & 0.129560 & $\mathrm{~ns}$ \\
\hline
\end{tabular}

Nota 1 : *** significativo a $1 ; * *$ significativo a $5 ; *$ significativo a $10 ;$ ns não significativo. Fonte: Autores.

\footnotetext{
${ }^{5}$ Todas as séries foram transformadas em logaritmo natural com o intuito de normalizar os desvios.
} 
Com base na Tabela 5, observa-se que as séries das exportações da indústria de transformação (LINDTRANSF), produtos não industriais (LPNI_STL) e abertura comercial (LABERT) foram estacionárias em nível, com 1\% de significância para o teste ADF; já as demais variáveis não foram estacionárias em nível. Por outro lado, os resultados da Tabela 6 indicaram, em ambos os testes, efetuada a primeira diferença, que as séries foram estacionárias, com 5\% de significância.

Tabela 6 - Testes de raiz unitária em primeira diferença aplicados nas séries mensais das exportações do Estado do Rio Grande do Sul da indústria da transformação e produtos não industriais (em US\$), taxa de câmbio real efetiva (R\$/ US\$), índice dos preços das commodities não energéticas e coeficiente de abertura comercial no período de janeiro de 2007 a dezembro de 2018.

\begin{tabular}{ccccccc}
\hline & \multicolumn{3}{c}{ Teste ADF } & \multicolumn{3}{c}{ Teste KPSS } \\
\hline Séries & Modelo & \multicolumn{2}{c}{ Estatística de teste } & Modelo & Estatística de teste \\
\hline LINDTRANSF & constante & -14.84910 & $* * *$ & constante & 0.266611 & $\mathrm{~ns}$ \\
LPNI_STL & constante & -11.60334 & $* * *$ & constante & 0.083447 & $\mathrm{~ns}$ \\
LTCREF & constante & -9.016943 & $* * *$ & constante & 0.192924 & $\mathrm{~ns}$ \\
LIPCOM & constante & -6.752766 & $* * *$ & constante & 0.116326 & $\mathrm{~ns}$ \\
LABERT & constante & -17.35743 & $* * *$ & constante & 0.048566 & $\mathrm{~ns}$ \\
\hline
\end{tabular}

Nota $1: * * *$ significativo a $1 ; * *$ significativo a $5 ; *$ significativo a $10 ;$ ns não significativo. Fonte: Autores.

Efetuados os testes de estacionariedade e identificada a ordem de integração, a próxima etapa consistiu em analisar individualmente a dinâmica das exportações da indústria da transformação e dos produtos não industriais do Estado do Rio Grande do Sul.

\subsection{Indústria de transformação do Estado do Rio Grande do Sul}

A fim de estimar os parâmetros do modelo econométrico que permitiu analisar as relações entre a indústria de transformação (em US\$), com taxa de câmbio real efetiva (R\$/ US\$), índice de preços das commodities não energéticas e coeficiente de abertura comercial, realizou-se o teste de cointegração de Johansen. Porém, para realizar esse teste, foi necessário, primeiramente, estimar um modelo VAR Auxiliar (Tabela 7). Para isso, foi essencial definir previamente o número ótimo de defasagens, por meio de um teste que permite identificar o comprimento dos lags.

Tabela 7 - Critério de defasagem do VAR auxiliar para a indústria da transformação.

\begin{tabular}{ccccccc}
\hline Defasagem & LogL & LR & FPE & AIC & SC & HQ \\
\hline 0 & 331.8335 & NA & $1.12 \mathrm{e}-07$ & -4.650121 & -4.566468 & -4.616128 \\
1 & 740.5505 & 788.4468 & $4.28 \mathrm{e}-10$ & -10.22057 & -9.802310 & -10.05061 \\
$\mathbf{2}$ & $\mathbf{7 8 5 . 3 0 7 1}$ & $\mathbf{8 3 . 7 9 9 7 2} *$ & $\mathbf{2 . 8 5 e - 1 0 *}$ & $\mathbf{- 1 0 . 6 2 8 4 7 *}$ & $\mathbf{- 9 . 8 7 5 5 9 5 *}$ & $\mathbf{- 1 0 . 3 2 2 5 3 *}$ \\
3 & $\mathbf{7 9 5 . 2 1 7 6}$ & 17.99353 & $3.11 \mathrm{e}-10$ & -10.54209 & -9.454608 & -10.10018 \\
\hline
\end{tabular}

Nota: Valor da verossimilhança (LogL); p-valor do teste de razão de verossimilhança (LR); Erro de Predição Final (FPE); Critério de Informação de Akaike (AIC); Critério de Informação Bayesiano de Schwarz (BIC); e o Critério de Informação de Hannan \& Quinn (HQC). Nota 2: *indica a defasagem ótima $(n)$ definida pelo critério.

Fonte: Autores.

Com base nos dados da Tabela 7, foi possível indicar que o número de defasagens foi de duas a serem incluídas no VAR, visto que, dos cinco critérios considerados, todos indicaram o mesmo número de defasagens do VAR auxiliar.

Após determinados os números de defasagens do modelo, procedeu-se ao teste de cointegração de Johansen, que permite demonstrar a existência, ou não, de relações de longo prazo entre as variáveis. Os resultados do teste do autovalor e do teste do traço estão esboçados na Tabela 8. 
Tabela 8 - Teste de cointegração de Johansen para a indústria da transformação.

\begin{tabular}{ccccc}
\hline & \multicolumn{2}{c}{ Estatística do Traço } & \multicolumn{2}{c}{ Estatística do Máximo Autovalor } \\
\hline & Calculado & P-valor & Calculado & P-valor \\
\hline $\mathbf{R}^{\mathbf{6}=\mathbf{0}}$ & $\mathbf{5 6 . 1 2 5 7 2} * * *$ & $\mathbf{0 . 0 0 0 6}$ & $\mathbf{3 6 . 9 7 5 6 9 * * *}$ & $\mathbf{0 . 0 0 0 6}$ \\
$\mathrm{R} \leq 1$ & 19.15003 & 0.1935 & 14.22587 & 0.1592 \\
$\mathrm{R} \leq 2$ & 4.924168 & 0.5782 & 4.914331 & 0.4894 \\
$\mathrm{R} \leq 3$ & 0.009837 & 0.9354 & 0.009837 & 0.9354 \\
\hline
\end{tabular}

Nota: *** significativo a $1 \%$. Fonte: Autores.

O teste de cointegração de Johansen revelou que a hipótese nula de que não há nenhum vetor de cointegração deve ser rejeitada ao nível de $1 \%$ para a estatística do traço e para a estatística do máximo autovalor (de acordo com os dados da Tabela 8). Além disso, o vetor de correção de erros que mais se ajustou foi o modelo 1 do sumário do teste, com as variáveis em nível sem tendência determinística e as equações de cointegração sem interceptos.

De acordo com a Tabela 9, que apresenta o vetor de cointegração (normalizado), todos os coeficientes estimados foram significativos ao nível de $1 \%$.

Tabela 9 - Estimativa do vetor de cointegração (normalizado) para a indústria da transformação.

\begin{tabular}{cccc}
\hline LINDTRANSF $(-1)$ & LTCREF $(-1)$ & LIPCOM $(-1)$ & LABERT $(-1)$ \\
\hline 1,0000 & $-2.051826^{* * *}$ & $-2.160808^{* * *}$ & $+0.777285^{* * *}$ \\
& $(0.14971)$ & $(0.17274)$ & $(0.23832)$ \\
& {$[-13.7049]$} & {$[-12.5090]$} & {$[3.26145]$} \\
\hline
\end{tabular}

Nota 1: LINDTRANSF = logaritmo neperiano das exportações da indústria da transformação do Estado do Rio Grande do Sul (US\$); LTCREF = logaritmo neperiano da taxa de câmbio real efetiva (R\$/ US\$); LIPCOM = logaritmo neperiano do índice de preços das commodities não energéticas; LABERT = logaritmo neperiano do coeficiente de abertura comercial. Nota 2: os valores entre parênteses referem-se ao erro padrão, e os entre colchetes, à estatística t. Nota 3: *** significativo a 1; ** significativo a 5, ns não significativo. Fonte: Autores.

Na Equação (7), é apresentado o vetor de cointegração (normalizado), indicando o relacionamento de longo prazo entre as variáveis com as respectivas elasticidades.

$$
\text { LINDTRANSF }_{t}=+2,05 \text { LTCREF }_{t}+2,16 \text { LIPCOM }_{t}-0,78 \operatorname{LABERT}_{\mathrm{t}}
$$

De acordo com a Equação (7), verifica-se que um aumento de $1 \%$ na taxa de câmbio real efetiva (R\$/ US\$), ou seja, uma desvalorização cambial ocasiona um acréscimo de 2,05\% nas exportações da indústria de transformação do Estado do Rio Grande do Sul. Esse resultado vai ao encontro dos estudos de Bresser-Pereira (2012; 2019), Cano (2012), Veríssimo e Araújo (2016) e Teixeira, Coronel e Oreiro (2019), dentre outros economistas do Novo Desenvolvimentismo, que demonstraram empiricamente a importância da desvalorização cambial visando fomentar as exportações da indústria de transformação e estancar o processo de desindustrialização.

Ainda, de acordo com a Equação (7), o aumento de $1 \%$ no índice de preços das commodities não energéticas ocasiona um acréscimo de 2,16\% nas exportações da indústria da transformação do Estado do Rio Grande do Sul. Esse resultado também foi encontrado por Veríssimo e Araújo (2016), que analisaram o processo de desindustrialização no estado de Minas Gerais, e por Souza e Veríssimo (2019), que analisaram o processo de desindustrialização na Região Sudeste do país e encontraram resultados positivos para os estados de Minas Gerais e São Paulo. Conforme os autores, para Minas Gerais, uma

${ }^{6}$ Indica o número de vetores de cointegração. 
possível explicação, a qual também tem a mesma congruência para a Região Sul, está relacionada às características de sua indústria baseada em recursos naturais e trabalho.

Também foi possível inferir, com base na Equação (7), que o aumento de $1 \%$ no coeficiente de abertura comercial ocasiona uma redução de 0,78\% nas exportações da indústria da transformação do Estado do Rio Grande do Sul. Esse resultado vai ao encontro dos estudos sobre desindustrialização de Palma (2005), Cano (2012) e Bresser-Pereira (2019), dentre outros, que demonstraram a forma desordenada com que foi feita a abertura comercial no país.

Com a finalidade de diagnóstico do modelo, foram realizados dois testes de correlação serial para os resíduos, cujos resultados encontram-se na Tabela 10.

Tabela 10 - Testes de correlação serial para os resíduos do modelo VEC para a indústria da transformação.

\begin{tabular}{ccccccc}
\hline \multicolumn{4}{c}{ Teste de Portmanteau } & \multicolumn{2}{c}{ Teste LM } \\
\hline Defasagens & Est. Q & p-valor & Est Ajust.Q & p-valor & Est. LM & p-valor \\
\hline 1 & 0.795499 & --- & 0.801181 & --- & 15.23148 & 0.5078 \\
2 & 5.726317 & --- & 5.802946 & --- & 15.22045 & 0.5086 \\
3 & 22.40004 & 0.7624 & 22.83914 & 0.7410 & 23.10563 & 0.1109 \\
4 & 30.91388 & 0.9320 & 31.60156 & 0.9190 & 9.974984 & 0.8679 \\
5 & 48.48300 & 0.8567 & 49.81661 & 0.8229 & 19.64731 & 0.2365 \\
6 & 61.94048 & 0.8779 & 63.87219 & 0.8381 & 14.60701 & 0.5536 \\
7 & 79.90486 & 0.8117 & 82.77502 & 0.7437 & 19.34905 & 0.2510 \\
8 & 99.64357 & 0.7048 & 103.7010 & 0.5991 & 22.15562 & 0.1382 \\
9 & 113.8307 & 0.7329 & 118.8554 & 0.6136 & 15.93766 & 0.4573 \\
10 & 123.2522 & 0.8422 & 128.9961 & 0.7375 & 10.81632 & 0.8207 \\
11 & 138.9711 & 0.8323 & 146.0451 & 0.7047 & 17.87557 & 0.3312 \\
\hline
\end{tabular}

Fonte: Autores.

Com base na análise dos dados apresentados na Tabela 10, o teste, com até onze defasagens, indicou que não existem problemas de correlação serial, com 1\% de significância. Dessa forma, os resultados de diagnóstico do modelo estimado são válidos e apresentam um relacionamento correto e confiável entre as variáveis em questão.

Para a análise da dinâmica das variáveis do modelo, foi utilizado um instrumento proporcionado pelo modelo VAR/VEC, que é a decomposição da variância dos erros de previsão.

$\mathrm{Na}$ Tabela 11, apresentam-se os resultados relativos à decomposição da variância dos erros de previsão para as exportações da indústria da transformação.

Tabela 11 - Resultados da decomposição da variância dos erros de previsão em porcentagem para as variáveis LINDTRANSF, LTCREF, LIPCOM e LABERT no período de janeiro de 2007 a dezembro de 2018

\begin{tabular}{cccccc}
\hline Variável & Período (meses) & LINDTRANSF & LTCREF & LIPCOM & LABERT \\
\hline LINDTRANSF & 1 & 100.0000 & 0.000000 & 0.000000 & 0.000000 \\
& 6 & 80.17143 & 4.004607 & 9.431316 & 6.392644 \\
& 12 & 61.46251 & 4.473577 & 22.67691 & 11.38701 \\
& 18 & 53.22784 & 4.904370 & 28.59330 & 13.27449 \\
& 24 & 48.19451 & 5.155773 & 32.21035 & 14.43936 \\
\hline
\end{tabular}

Fonte: Autores.

Os resultados da decomposição da variância dos erros de previsão das exportações da indústria da transformação (LINDTRANSF), apresentados na Tabela 11, mostram que, decorridos 24 meses após um choque não antecipado sobre essa variável, 48,19\% de seu comportamento devem-se a ela própria, sendo que os 51,81\% restantes são atribuídos às demais variáveis, 5,16\% à taxa de câmbio real efetiva (LTCREF), 32,21\% ao índice de preços das commodities não energéticas 
(LIPCOM) e 14,44\% ao coeficiente de abertura comercial (LABERT). Esse resultado mostra que o índice de preços das commodities não energéticas possui elevada influência sobre as exportações da indústria de transformação, podendo ser um indício de uma especialização em bens intensivos em recursos naturais e mais um indicativo do processo de reprimarização da economia.

\subsection{Produtos não industriais do Estado do Rio Grande do Sul}

Para realização do teste de cointegração, é necessário verificar o número de defasagens para inserir do modelo, conforme Tabela12.

Tabela 12 - Critério de defasagem do VAR auxiliar para os produtos não industriais.

\begin{tabular}{ccccccc}
\hline Defasagem & LogL & LR & FPE & AIC & BIC & HQC \\
\hline 1 & 691.4297 & NA & $8.12 \mathrm{e}-10$ & -9.580563 & $-9.245952 *$ & -9.444588 \\
$\mathbf{2}$ & 719.0640 & $\mathbf{5 2 . 1 3 2 8 5} *$ & $\mathbf{6 . 8 8 e}^{*} \mathbf{1 0}$ & $\mathbf{- 9 . 7 4 5 5 8 9 *}$ & -9.076367 & $\mathbf{- 9 . 4 7 3 6 4 0 *}$ \\
3 & 731.4005 & 22.57320 & $7.26 \mathrm{e}-10$ & -9.693624 & -8.689791 & $\mathbf{- 9 . 2 8 5 7 0 1}$ \\
\hline
\end{tabular}

Nota 1: valor da verossimilhança ( $\log \mathrm{L})$; p-valor do teste de razão de verossimilhança (LR); Erro de Predição Final (FPE); Critério de Informação de Akaike (AIC); Critério de Informação Bayesiano de Schwarz (BIC); e o Critério de Informação de Hannan \& Quinn (HQC). Nota 2: *indica a defasagem ótima $(n)$ definida pelo critério.

Fonte: Autores.

Com base nos dados da Tabela 12, foi possível indicar que duas defasagens devem ser incluídas no VAR, visto que, dos cinco critérios considerados, quatro indicaram o mesmo número de defasagens do VAR auxiliar.

O teste de cointegração de Johansen revelou que a hipótese nula de que não há nenhum vetor de cointegração deve ser rejeitada ao nível de $1 \%$ (de acordo com os dados da Tabela 13). Além disso, o vetor de correção de erros que mais se ajustou foi o modelo 1 do sumário do teste, com as variáveis em nível sem tendência determinística e as equações de cointegração sem interceptos.

Tabela 13 - Teste de cointegração de Johansen para os produtos não industriais.

\begin{tabular}{|c|c|c|c|c|}
\hline & \multicolumn{2}{|c|}{ Estatística do Traço } & \multicolumn{2}{|c|}{ Estatística do Máximo Autovalor } \\
\hline & Calculado & P-valor & Calculado & P-valor \\
\hline $\mathbf{R}=\mathbf{0}$ & $53.10383 * * *$ & 0.0016 & $30.87672 * * *$ & 0.0053 \\
\hline $\mathrm{R} \leq 1$ & 22.22711 & 0.0887 & 16.52181 & 0.0769 \\
\hline $\mathrm{R} \leq 2$ & 5.705298 & 0.4729 & 5.555326 & 0.4030 \\
\hline $\mathrm{R} \leq 3$ & 0.149972 & 0.7490 & 0.149972 & 0.7490 \\
\hline
\end{tabular}

Nota: ** significativo a 5 e $* * *$ significativo a 1 . Fonte: Autores.

De acordo com a Tabela 14, que apresenta o vetor de cointegração (normalizado), todos os coeficientes foram significativos ao nível de $1 \%$.

Tabela 14 - Estimativa do vetor de cointegração (normalizado) para a transformação não industrial.

\begin{tabular}{cccc}
\hline LPNI_STL $(-1)$ & LTCREF $(-1)$ & LIPCOM $(-1)$ & LABERT $(-1)$ \\
\hline 1,0000 & $-2.601670 * * *$ & $-0.925549 * * *$ & $+2.254532^{* * *}$ \\
& $(0.27986)$ & $(0.32022)$ & $(0.43960)$ \\
& {$[-9.29637]$} & {$[-2.89039]$} & {$[5.12857]$} \\
\hline
\end{tabular}

Nota 1: LPNI_STL = logaritmo neperiano das exportações dos produtos não industriais do Estado do Rio Grande do Sul - dessazonalizada pelo método Seazonal-trend Decomposition - STL (US\$); LTCREF = logaritmo neperiano da taxa de câmbio real efetiva (R\$/ US\$); LIPCOM = logaritmo neperiano do índice de preços das commodities não energéticas; LABERT = logaritmo neperiano do coeficiente de abertura comercial; $\mathrm{C}=$ constante. Nota 2: os valores entre parênteses referem-se ao erro padrão, e os entre colchetes, à estatística t. Nota 3: $* * *$ significativo a $1 ; * *$ significativo a 5 , ns não significativo.

Fonte: Autores. 
Na Equação (8), é apresentado o vetor de cointegração (normalizado), indicando o relacionamento de longo prazo entre as variáveis com as respectivas elasticidades.

$$
\text { LPNI_STL }_{t}=+2,60 \text { LTCREF }_{t}+0,93 \text { LIPCOM }_{t}-2,25 \text { LABERT }_{t}
$$

De acordo com a Equação (8), verifica-se que um aumento de $1 \%$ na taxa de câmbio real efetiva (R\$/ US\$), desvalorização cambial, ocasiona um acréscimo de 2,60\% nas exportações dos produtos não industriais do Estado do Rio Grande do Sul, o que vai ao encontro de Bresser-Pereira, Oreiro e Marconi (2016).

Ainda, de acordo com a Equação (8), o aumento de $1 \%$ no índice de preços das commodities não energéticas ocasiona um acréscimo de $0,93 \%$ nas exportações dos produtos não industriais do Estado do Rio Grande do Sul. Embora esse resultado não fosse o esperado, uma possível explicação para isso, conforme Veríssimo e Araújo (2016, p. 131), que encontraram resultado positivo para a indústria extrativa de Minas Gerais, e que também pode ser utilizado para explicar o caso do Rio Grande do Sul, é que "o contexto de elevados preços externos das commodities tende a beneficiar o desempenho do estado neste caso".

Também foi possível inferir, com base na Equação (8), que o aumento de $1 \%$ no coeficiente de abertura comercial ocasiona uma redução de 2,25\% nas exportações dos produtos não industriais do Estado do Rio Grande do Sul, conforme era esperado e já explicado pelos teóricos do Novo Desenvolvimentismo citados neste trabalho.

Com a finalidade de diagnóstico do modelo, foram estimados testes de correção serial para os resíduos, cujos resultados encontram-se na Tabela 15.

Tabela 15 - Teste de correlação serial para os resíduos do modelo VEC para os produtos não industriais.

\begin{tabular}{ccccccc}
\hline \multicolumn{5}{c}{ Teste de Portmanteau } & \multicolumn{2}{c}{ Teste LM } \\
\hline Defasagens & Est. Q & p-valor & Est Ajust.Q & p-valor & Est. LM & p-valor \\
\hline 1 & 1.190096 & --- & 1.198597 & --- & 20.96527 & 0.1798 \\
2 & 3.517452 & -- & 3.559440 & --- & 16.26760 & 0.4344 \\
3 & 15.99633 & 0.9659 & 16.30960 & 0.9610 & 17.13203 & 0.3771 \\
4 & 23.77832 & 0.9945 & 24.31880 & 0.9930 & 9.017501 & 0.9127 \\
5 & 35.19865 & 0.9956 & 36.15899 & 0.9937 & 12.11245 & 0.7362 \\
6 & 47.61352 & 0.9956 & 49.12564 & 0.9929 & 13.07120 & 0.6675 \\
7 & 67.81438 & 0.9725 & 70.38177 & 0.9544 & 21.56571 & 0.1578 \\
8 & 78.17277 & 0.9864 & 81.36321 & 0.9739 & 11.28114 & 0.7918 \\
9 & 91.05280 & 0.9884 & 95.12142 & 0.9748 & 14.47589 & 0.5633 \\
10 & 106.1192 & 0.9852 & 111.3379 & 0.9645 & 17.98666 & 0.3247 \\
11 & 116.8189 & 0.9918 & 122.9429 & 0.9764 & 11.16438 & 0.7992 \\
\hline
\end{tabular}

Fonte: Autores.

Com base na análise dos dados apresentados na Tabela 15, até onze defasagens, o teste indicou, com 5\% de significância, que não existe problema de autocorrelação serial. Dessa forma, os resultados de diagnóstico do modelo estimado são válidos e apresentam um relacionamento correto e confiável entre as variáveis em questão.

Na Tabela 16, apresentam-se os resultados relativos à decomposição da variância dos erros de previsão para o modelo dos produtos não industriais. 
Tabela 16 - Resultados da decomposição da variância dos erros de previsão em porcentagem para as variáveis LPNI_STL, LTCREF, LIPCOM e LABERT no período de janeiro de 2007 a dezembro de 2018.

\begin{tabular}{cccccc}
\hline Variável & Período (meses) & LPNI_STL & LTCREF & LIPCOM & LABERT \\
\hline LPNI_STL & 1 & 100.0000 & 0.000000 & 0.000000 & 0.000000 \\
& 6 & 90.06909 & 0.584331 & 1.692555 & 7.654024 \\
& 12 & 84.91718 & 0.352727 & 2.626401 & 12.10369 \\
& 18 & 82.96696 & 0.259426 & 3.030926 & 13.74269 \\
& 24 & 81.92595 & 0.209643 & 3.247105 & 14.61730 \\
\hline
\end{tabular}

Fonte: Autores.

Os resultados da decomposição da variância dos erros de previsão das exportações dos produtos não industriais (LTNI_STL), apresentados na Tabela 16, mostram que, decorridos 24 meses após um choque não antecipado sobre essa variável, $81,93 \%$ de seu comportamento devem-se a ela própria, sendo que os 18,07\% restantes são atribuídos às demais variáveis, $0,21 \%$ à taxa de câmbio real efetiva (LTCREF), 3,25\% ao índice de preços das commodities não energéticas (LIPCOM) e 14,62\% ao coeficiente de abertura comercial (LABERT). Convém destacar que, para os produtos não industriais, as demais variáveis analisadas neste trabalho, taxa de câmbio, índice de preços das commodities não energéticas e abertura comercial, não têm um impacto de tão forte magnitude como para a indústria de transformação.

\section{Conclusões}

O presente trabalho visou responder se está ocorrendo um processo de desindustrialização no Estado do Rio Grande do Sul, e, neste sentido, utilizou-se de revisão bibliográfica, análise estatística e da estimação de um modelo econométrico VEC.

Em relação à análise econométrica, constatou-se que a desvalorização cambial estimula as exportações e, portanto, em qualquer ação visando fomentar a competitividade do setor industrial, esta variável deve ser utilizada, bem como, se for apreciada, leva à perda de competitividade industrial. A abertura comercial mostrou-se extremamente nociva às exportações tanto da indústria de transformação como dos produtos não industriais. A variável índice de preço das commodities não energéticas apresentou sinal contrário ao esperado, contudo uma possível explicação para isso está relacionada ao perfil e à estrutura das exportações da região.

Com este trabalho, avançou-se no sentido de estudar o processo de desindustrialização para o Estado do Rio Grande do Sul; contudo, não se pode generalizar os resultados para as demais regiões brasileiras. Além disso, uma limitação do trabalho está relacionada às variáveis macroeconômicas utilizadas, ou seja, utilizou-se apenas três, as mais utilizadas na literatura econômica e nos trabalhos sobre desindustrialização. Contudo isto, de uma certa forma, limita um pouco a análise, visto que não contempla uma análise com maior acuidade sobre este processo.

Nesse sentido, sugere-se, para estudos futuros, a incorporação de outras variáveis macroeconômicas, bem como a estimação através de dados em painel com efeitos fixos e aleatórios, bem como a utilização de Modelos de Equilíbrio Geral Computável (MEGC), os quais são ferramentas que contribuem para verificar como o processo de desindustrialização influência nos níveis de bem-estar da população, no Produto Interno Bruto (PIB), bem como nos fluxos econômicos e nas finanças públicas das regiões de análise.

\section{Referências}

Acemoglu, D., \& Robinson, J. (2012). Por que as nações fracassam: as origens do poder, da prosperidade e da pobreza. Elsevier.

Amisano, G, \& Giannini, C. (1997). Topics in structural VAR econometrics. (2a ed.), Spring-Verlag. 
Banco Central Do Brasil (BC). (2021). Penetração de importados e coeficiente de exportação da indústria de transformação. 2019. $<$ https://www.bcb.gov.br/conteudo/relatorioinflacao/EstudosEspeciais/Penetracao_de_importados_e_coeficiente_de_exportacao_da_industria_de_transformac ao.pdf $>$.

Barros, O. de, \& Pereira, R. R. (2008). Desmistificando a tese de desindustrialização: reestruturação da indústria brasileira em uma época de transformações globais. In: Barros, O. de, Giambiagi, F. (Org.). Brasil Globalizado. Elsevier.

Bender Filho, R., \& Coronel, D. A. (2017). Desindustrialização na economia gaúcha: evidências a partir de indicadores de orientação externa. In: Calandro, M. L., Miebach, A. D., Alvim, A. M. (Org.). Inovação, sustentabilidade e desenvolvimento no RS. Porto Alegre: FEE.

Benjamin, C. (2015). Desindustrialização: pode o Brasil sobreviver sem um expressivo setor industrial? Boletim Conjuntura Brasil, Fundação João Mangabeira, n. 2.

Bonelli, R., \& Pessoa, S. (2017). Desindustrialização no Brasil: um resumo da evidência. Centro de Desenvolvimento Econômico, FGV, 2010. (Texto para Discussão). <http://www.fgv.br/mailing/ibre/carta/agosto.2010/CIBRE_agosto_2010.pdf>

Bonelli, R., Pessoa, S., \& Matos, S. (2013). Desindustrialização no Brasil: fatos e interpretação. In: Bacha, E., Bolle, M. B. (Org.). O futuro da indústria no Brasil: desindustrialização em debate. Rio de Janeiro: Civilização Brasileira.

Box, G. E. P., \& Pierce, D. A. (1970). Distribution of residual autocorrelations in autoregressive integrated moving average time series models. Journal of the American Statistical Association, 65(332), 1509-1526.

Brandt, P. T., \& Williams, J. T. (2007). Multiple Time Series Models. Sage.

Breitung, J, Brüggemann, R., \& Lütkepohl, H. (2004). Structural vector autoregressive modeling and impulse responses. In: Lütkepohl, H., Krätzig, M. (Ed.). Applied time series econometrics. Cambridge University Press.

Brooks, C. (2008). Introductory Econometrics for Finance. Cambridge University Press.

Bresser-Pereira, L. C. (2009a). Getúlio Vargas: o estadista, a nação e a democracia. <http://www.bresserpereira.org.br/listar〉.

Bresser-Pereira, L. C. (2009b). Globalização e competição: porque alguns países emergentes têm sucesso e outros não. Elsevier.

Bresser-Pereira, L. C. (2011). A taxa de câmbio no centro da teoria do desenvolvimento <http://www.bresserpereira.org.br/papers/2011/11.24.Macro_cambio_teoria_desenvolv_n_destin.pdf>.

Bresser-Pereira, L. C. (2012). Desprotecionismo e desindustrialização. <http://www.bresserpereira.org.br/articles/2012/97.Desprotecionismo.pdf

Bresser-Pereira, L. C. (2019). 40 anos de desindustrialização. <http://www.bresserpereira.org.br/view.asp?cod=7636>.

Bresser-Pereira, L. C, Oreiro, J. L, \& Marconi, N. (2016). Macroeconomia desenvolvimentista. Campus.

Breusch, T. S. (1978).Testing for autocorrelation in dynamic linear models. Australian Economic Papers, 17(1).

Bueno, R. L. S. (2015). Econometria de séries temporais. (2a ed.), Cengage Learning.

Cano, W. (2012). A desindustrialização no Brasil. Economia e Sociedade, 21, 831-851.

Cano, W. (2014). (Des)Industrialização e (Sub) Desenvolvimento. Cadernos do desenvolvimento, 9(15), 139-174.

Colombo, A. O., Felipe, E. S., \& Sampaio, D. (2019). A desindustrialização no Brasil: um processo, várias vertentes. In: Encontro Internacional da Associação Keynesiana Brasileira. Anais... Campinas (SP) IE-UNICAMP. <https//www.even3.com.br/anais/akb/172464-a-desindustrializacao-no-brasil--umprocesso-varias-vertentes>.

Coronel, D. A. (2013). Impactos da política de desenvolvimento produtivo na economia brasileira. Prismas.

Coronel, D. A. (2019). Processo de desindustrialização da Economia Brasileira e possibilidades de reversão. Revista de Economia e Agronegócio, 17(3), 389398.

Coronel, D. A. (2020). Análise do processo de desindustrialização na região Sul do Brasil: uma abordagem por meio de econometria de séries temporais. Monografia (Especialização em Estatística e Modelagem Quantitativa) - Universidade Federal de Santa Maria.

Coronel, D. A., Azevedo, A. F. Z. de, \& Campos, A. C. (2014). Política industrial e desenvolvimento econômico: a reatualização de um debate histórico. Revista de Economia Política, 34(1), 103-119.

Dickey, D. A., \& Fuller, W. A. (1979). Distribution of the estimators for autoregressive time series with a unit root. Journal of the American Statistical Association, 74(366), 427-431.

Dickey, D. A., \& Fuller, W. (1981). A Likelihood ratio statistic for autoregressive time series with a unit root. Econometrica, 49(4), $1057-1073$.

Enders, W. (2015). Applied Econometric Time Series. (4a ed.), Wiley.

Engle, R. F., \& Granger, C. W. (1987). Co-integration and error-correction: representation, estimation and testing. Econometrica, Chicago, 55(2), 251-276.

Ferreira, P. C., \& Hamdan, G. (2003). Política industrial no Brasil: ineficaz e regressiva. Econômica, 5(2), 305-316.

Fundação Centro de Estudos do Comércio Exterior - FUNCEX. (2021). Estatísticas. 〈https://www.funcex.org.br〉. 
Gelatti, E. et al. (2019). Desindustrialização no brasil: uma análise à luz das exportações e importações - 1997 a 2018. In: Salão do conhecimento bioeconomia: diversidade e riqueza para o desenvolvimento sustentável - UNIJUÍ - XXIV Jornada de Pesquisa, 2019, Panambi-RS-Brasil. Anais... Panambi.

Godfrey, L. G. (1987). Testing against general autoregressive and moving average error models when the regressor include lagged dependent variables. Econometrica, 46(6), 1293-1302.

Greene, W. H. (2008). Econometrics Analysis. (6a ed.), Pearson Education.

Hamilton, J. D. (1994). Time series analysis. Princeton University Press.

Harris, R. I. D. (1995). Using cointegration analysis in econometric modelling. Prentice-Hall-Harvester Wheatsheaf.

Instituto Brasileiro de Geografia e Estatísticas - IBGE. (2021). Contas Regionais do Brasil. <http://biblioteca.ibge.gov.br/>.

Instituto de Pesquisa Econômica Aplicada - IPEA. (2021). Macroeconômico. 〈http://www.ipeadata.gov.br〉.

Jank, M. S. et al. (2008). Exportações: existe uma "doença brasileira"? In: Barros, O. de, Giambiagi, F. (Org.). Brasil Globalizado. Elsevier.

Johansen, S. (1988). Statistical analysis of cointegration vectors. Journal of Economic Dynamic and Control, 12(2-3), 231-254.

Johansen, S. (2014). Times series cointegration. Creates Research Paper, n. 38.

Kaldor, N. (1957). A model of economic growth. Economic Journal, 67(268), 591-624.

Kaldor, N. (1966). Causes of the slow rate of economic growth of the United Kingdom. Cambridge University Press.

Kaldor, N. (1978). Causes of the low rate of growth of the United Kingdom. Further Essays in Economic, Growth, London Duckworth.

Koop. G. (2006). Analysis of financial data. John Wiley \& Sons Ltd.

Kwiakowski, D. et al. (1992). Testing the alternative of stationary against the alternative of a unit root: how sure are we that economic time series have a unit root? Journal of Econometrics, 54, 159-178.

Kupfer, D. (2003). Política industrial. Econômica, 5(2), 281-298.

Libânio, G., Moro, S., \& Londe, A. C. (2014). Qualidade das exportações e crescimento econômico nos anos 2000. Encontro nacional de economia - ANPEC, 42. Anais... Natal.

Ljung, G. M., \& Box, G. E. P. (1978). On a measure of lack of fit in time series models. Biometrika, 65(2), $297-303$.

Lütkepohl, H. (2007). New introduction to multiple time series analysis. Springer, 2007.

Lütkepohl, H. (2011). Vector autoregressive models. EUI Working Paper, n.30.

Marconi, N. (2015). A doença holandesa e o valor da taxa de câmbio. In: Oreiro, J. L., De Paula, L. F., Marconi, N. (Org.). A teoria econômica na obra de Bresser-Pereira. Santa Maria: Ed. UFSM.

Marconi, N., \& Rocha, M. (2011). Desindustrialização precoce e sobrevalorização da taxa de câmbio. Brasília: IPEA (Texto para discussão 1681).

Mattei, L., Scaramuzzi, T. (2016). A taxa de câmbio como instrumento do desenvolvimento econômico. Revista de Economia Política, $36(4), 726-747$.

Ministério do Desenvolvimento Indústria e Comercio Exterior - MDIC. (2021). Estatísticas do comércio exterior. <http://www.comexbrasil.gov.br/conteudo/ver/chave/secex/menu/211〉.

Nassif. A. (2019). Política industrial e desenvolvimento econômico: teoria e propostas para o Brasil na era da economia digital. In: Feijo, C., Araújo, E. (Orgs.). Macroeconomia moderna: lições de Keynes para economias em desenvolvimento. Elsevier.

Oreiro, J. L., \& Feijó, C. A. (2010). Desindustrialização: conceituação, causas, efeitos e o caso brasileiro. Revista de Economia Política, 30(2), $219-232$.

Organização para a Cooperação e Desenvolvimento Econômico - OCDE. (2019). Industry and entrepreneurship. <http://www.oecd.org/topic/ 0,3373,en_2649_37461_1_1_1_1_37461,00.html>.

Palma, J. G. (2005). Four sources of deindustrialization and a new concept of the Dutch disease. In: Ocampo, J. A. (Ed.). Beyond Reforms. Palo Alto: Stanford University Press.

Pack, H., \& Saggi, K. (2006). Is there a case for industrial policy? A critical survey. The Word Banck Research Observer, 21(2), $267-297$.

Pereira, W. M., \& Cario, S. A. F. (2017). Indústria, desenvolvimento econômico e desindustrialização: sistematizando o debate no Brasil. Economia $e$ Desenvolvimento, 29(1), 587-609.

Pereira, A. S, Shitsuka, D. M, Parreira, F. J., \& Shitsuka, R. (2018). Metodologia da pesquisa científica. UFSM. https://repositorio.ufsm.br/bitst ream/ha ndle/1/15824/Lic_Computacao_Metodologia-Pesquisa-Cientifica.pdf?sequence=1.

Peres, W. (2006). The slow comeback of industrial policy in Latin America and the Caribbean. CEPAL Review, Chile, 88(1), 71-88. 
Research, Society and Development, v. 10, n. 2, e43510212784, 2021

(CC BY 4.0) | ISSN 2525-3409 | DOI: http://dx.doi.org/10.33448/rsd-v10i2.12784

Peres, S. C. et al. (2018). Uma investigação sobre os determinantes da desindustrialização: teorias e evidências para países desenvolvidos e em desenvolvimento (1970-2015). In: Encontro de economia da região sul (ANPEC-SUL), 21, Curitiba-PR-Brasil. Anais.

Pinheiro, M. C. et al. (2007). Porque o Brasil não precisa de política industrial. FGV, 2007. (Texto para discussão 644).

Pinto, N. G. M., Silva, M. L., \& Coronel, D. A. (2015). O processo de desindustrialização: um levantamento sobre a produção científica na base do Scopus. Revista de Administração da UEG, 6(3), 78-88.

Pochmann, M. (2016). Brasil sem industrialização: a herança renunciada. Editora da UEPG.

Reinert, E. S. (2016). Como os países ricos ficaram ricos... e porque os países pobres continuam pobres. Rio de Janeiro: Contraponto.

Rowthorn, R., \& Ramaswamy, R. (1999). Growth, trade and deindustrialization. Washington: International Monetary Fund Staff Papers, 46(1).

Shumway, R. H., \& Stoffer, D. S. (2006). Times series analysis and its applications with R examples. Springer.

Silva, J. A. (2019). A desindustrialização na região Sul. Cadernos Metropolitanos, 21(45), 531-550.

Silva, M. L. et al. (2019). O setor industrial brasileiro frente à integração econômica. Poisson.

Soares, C. S., Coronel, D. A., \& Marion Filho, P. J. (2013). A recente política industrial brasileira: da política de desenvolvimento Produtivo ao Plano Brasil Maior. Perspectivas Contemporâneas, 8(1), 1-20.

Sonaglio, C. M. et al. (2010). Evidências de desindustrialização no Brasil: uma análise com dados em painel. Economia Aplicada, 14(4), 347-372.

Souza, I. E. L. de, \& Veríssimo, M. P. (2019). Produção e emprego industrial nos estados brasileiros: evidências de desindustrialização. Nova Economia (UFMG), 29(1), 75-101.

Squeff, G. C. (2012). Desindustrialização: luzes e sombras no debate brasileiro. Brasília: IPEA (Texto para discussão 1747).

Strack, D., \& Azevedo, A. F. Z. (2012). A doença holandesa no Brasil: sintomas e efeitos. Economia e Desenvolvimento, 24(2), 68-91.

Stumm, M. G., Nunes, W., \& Perissinotto, R. (2019). Ideias, instituições e coalizões: as razões do fracasso da política industrial lulista. Revista de Economia Política, 39(4), 736-754.

Szirmai, A. (2012). Industrialisation as an engine of growth in developing countries, 1950-2005. Structural change and economic dynamics, 23(4), 406-420.

Teixeira, F. O. et al. (2018). Grau de especialização da cesta de exportaçães e sua relação com o crescimento econômico dos estados brasileiros. In: Encontro de economia da região sul (ANPEC-SUL), 21, 2018, Curitiba-PR-Brasil. Anais.

Teixeira, F. O., Coronel, D. A., \& Oreiro, J. L. (2019). Principais determinantes do comportamento e da intensidade tecnológica das exportações brasileiras. In: Encontro internacional da associação keynesiana brasileira. Anais... Campinas (SP) IE-UNICAMP, 2019. <https//www.even3.com.br/anais/akb/171123principais-determinantes-do-comportamento-e-da-intensidade-tecnologica-das-exportacoes-brasileiras>

Veríssimo, M. P. (2010). Doença holandesa no Brasil: Ensaios sobre taxa de câmbio, perfil exportador, desindustrialização e crescimento econômico. 2010. Tese (Doutorado em Economia) - Universidade Federal de Uberlândia, 2010.

Veríssimo, M. P., \& Araújo, S. C. (2016). Perfil Industrial de Minas Gerais e a hipótese de desindustrialização estadual. Revista Brasileira de Inovação. Campinas, 15(1), 113-138.

World Bank. (2021). World Bank Commodity Price Data. <pubdocs.worldbank.org/en/561011486076393416/CMO-Historical-Data-Monthly.xlsx>. 